\title{
Distribuição volumétrica de calda contendo Metarhizium anisopliae
}

\author{
Volumetric distribution of spray containing Metarhizium anisopliae
}

\author{
Haroldo Xavier Linhares Volpe ${ }^{{ }^{*}}$ Rogério Teixeira Duarte $^{\mathrm{I}}$ Anderson Gonçalves da Silva ${ }^{\mathrm{I}}$ \\ Edison Baldan Júnior ${ }^{I I}$ Gilson José Leite ${ }^{\mathrm{I}}$ Marcelo da Costa Ferreira ${ }^{\mathrm{I}}$
}

\section{RESUMO}

O controle microbiano de Mahanarva fimbriolata é de suma importância para o manejo dessa praga em canade-açúcar, porém carece de melhorias quanto à tecnologia de aplicação. O trabalho teve como objetivo definir um modelo de bico de pulverização adequado para o controle de $\boldsymbol{M}$. fimbriolata, com base no padrão de distribuição de calda aspergida e espaçamento entre bicos. Utilizaram-se os bicos TF4, TTI e AIUB11004VS e caldas a base de fungo Metarhizium anisopliae sem adjuvante e com Agral a 2\% e 4\%. Avaliou-se o espaçamento entre bicos baseado na construção de curvas de deposição, considerando CV máximo de 10\%; ângulo de abertura e vazão dos bicos. Os maiores espaçamentos foram de $85 \mathrm{~cm}$ em calda com $2 \%$ de adjuvante para o bico TF4, $70 \mathrm{~cm}$ para AIUB11004VS sem adição de adjuvante e $55 \mathrm{~cm}$ para o bico TTI, independente da calda. Em relação ao ângulo de abertura, houve apenas diferença entre os bicos testados em uma mesma calda. A vazão foi maior para a calda com 4\% de adjuvante para os bicos TF4 e TTI, sendo que AIUB11004VS apresentou menores vazões em relação aos outros modelos para calda com $2 \%$ e $4 \%$ de adjuvante. Conclui-se que o modelo AIUB11004VS é uma importante ferramenta operacional, visando o controle de $\boldsymbol{M}$. fimbriolata, por apresentar menor consumo de calda e bons resultados de distância entre bicos.

Palavras-chave: tecnologia de aplicação, espaçamento entre pontas, controle biológico, controle microbiano, cigarrinha da cana-de-açúcar, Mahanarva fimbriolata, Metarhizium anisopliae.

\section{ABSTRACT}

The microbial control of Mahanarva fimbriolata is very important to management of this pest in sugarcane crops, however lacks improvement in spraying technology. The work aimed to evaluate a nozzle model adequate to control $\mathbf{M}$. fimbriolata, based on pattern of spray distribution and the space between nozzles. TF4, TTI and AIUB11004VS nozzles containing the fungus Metarhizium anisopliae without adjuvant, with Agral $2 \%$ and $4 \%$ were used in the assay. We evaluated spacing between nozzles by constructing deposition curves considering maximum CV of $10 \%$, spray angle and nozzle flow for different sprays. The larger nozzle spacings were $85 \mathrm{~cm}$ for spray with $2 \%$ of adjuvant and TF4 nozzle, $70 \mathrm{~cm}$ for AIUB11004VS without adjuvant addition and $55 \mathrm{~cm}$ TTI nozzle, independent of spray used. Despite the spray angle, we observed difference between the nozzles to the same spray. The flow was larger for spray with adjuvant at 4\%, to TF4 and TTI, while AIUB11004VS showed minor flows when compared to the others nozzles using $2 \%$ and $4 \%$ of adjuvant. By presenting good results of distance between nozzles and minor spray consumption, AIUB11004VS is a good tool for control of $\mathbf{M}$. fimbriolata.

Key words: application technology, spacing between nozzles, biological control, microbial control, root froghopper Mahanarva fimbriolata, Metarhizium anisopliae.

\section{INTRODUÇÃO}

Até meados da década de 1990, a cigarrinhadas-raízes, Mahanarva fimbriolata (Stål), era praga de pouca importância para a cana-de-açúcar no estado de São Paulo, pois a queima da palha antes da colheita mantinha suas populações baixas, principalmente pela destruição dos ovos em diapausa (DINARDOMIRANDA et al., 2004). Com o aumento da área colhida mecanicamente, houve considerável incremento na

\footnotetext{
'Departamento de Fitossanidade, Universidade Estadual Paulista Júlio de Mesquita Filho (Unesp), 14884-900, Jaboticabal, SP, Brasil. E-mail: hxlvolpe@ig.com.br. *Autor para correspondência.
}

"Suporte Técnico Usina São Martinho S.A, Pradópolis, SP, Brasil. 
população dessa praga (MACEDO et al., 1997), devido ao aumento significativo da umidade e da matéria orgânica do solo, em função do depósito de palha sobre ele (ALMEIDA et al., 2003; DINARDO-MIRANDA etal., 2004).

Para o controle da cigarrinha-das-raízes, uma série de medidas pode ser recomendada, como o controle cultural, biológico e o químico (ALMEIDA et al., 2003). O controle biológico com macro ou microrganismos é um dos principais componentes do manejo integrado de cigarrinhas (ALVES \& ALMEIDA, 1997). A ocorrência natural do fungo Metarhizium anisopliae(Metsch.) atacando cigarrinha-das-raízes em canaviais de todo o país é bastante comum e incentiva o uso desse agente de controle biológico em áreas infestadas por essa praga. Esforços têm sido despendidos em estudos para uso do fungo em um programa de manejo integrado da cigarrinha (DINARDO-MIRANDA et al., 2004).

A tecnologia de aplicação de produtos fitossanitários é diretamente responsável pela correta colocação dos produtos fitossanitários no alvo, cuidando da preservação do ambiente e da saúde do trabalhador, sem descuidar da técnica e da rentabilidade da produção (MATUO, 1990). A curva característica de distribuição volumétrica tem grande importância na determinação da distância do bico em relação ao alvo e no espaçamento entre eles na barra de pulverização, sendo que a sobreposição do jato de um bico hidráulico convencional com os adjacentes é importante para uniformizar a distribuição do líquido pulverizado (MATTHEWS, 2000). Essa uniformidade é diretamente alterada pelo espaçamento entre pontas, pressão de trabalho, altura da barra em relação ao alvo e ângulo de abertura do jato das pontas de pulverização (FERNANDES et al., 2007).

Uma das formas de quantificar a uniformidade de distribuição em uma pulverização é por meio da análise da deposição do produto na área, expressa pelo coeficiente de variação (CV), pois, quanto menor esse valor, mais uniforme é a distribuição (FAO, 1997). Os padrões adequados de CV são de 10 a 15\% (FAO, 1997). Valores acima desse limite indicam distribuição desuniforme de calda, ocasionado por pontas desgastadas, pontas diferentes na barra, espaçamento variado entre bicos ou má qualidade das pontas de pulverização acarretando controle ineficiente (FAO, 1997; FERNANDES et al., 2007).

Atualmente, na região de Jaboticabal, aproximadamente 100 mil hectares plantados com canade-açúcar são pulverizados via aérea $\operatorname{com} \boldsymbol{M}$. anisopliae. Porém, não há trabalhos na literatura com informações que possam auxiliar na escolha do bico com melhor distribuição e menor consumo de calda, sobretudo em aplicações terrestres que também vêm sendo praticadas a campo em diversas áreas de produção por todo o Brasil. Dessa forma, as aplicações vêm sendo realizadas de maneira empírica, aproveitando conhecimentos de outras modalidades de aplicação, porém, que podem oferecer resultados diferentes em relação à distribuição da calda, devido a características físicas e químicas intrínsecas de cada formulação utilizada.

Dessa forma, o trabalho teve como objetivo definir um modelo de bico de pulverização adequado para o controle de cigarrinha-das-raízes em áreas de plantios comerciais de cana-de-açúcar, com base no padrão de distribuição de calda aspergida e espaçamento entre bicos na barra do pulverizador.

\section{MATERIAL E MÉTODOS}

O experimento foi realizado no Laboratório de Ciência das Plantas Daninhas do Departamento de Fitossanidade da UNESP, Campus de Jaboticabal, com temperatura de 21 a $25^{\circ} \mathrm{C}$ e umidade relativa de $60 \%$.

Para a avaliação da distribuição da calda pulverizada pela ponta, foi utilizada mesa de deposição para pontas de pulverização hidráulica constituída de uma chapa de metal corrugado, formando canaletas em "V", distanciada 2,5cm entre si, num total de 67 canaletas, que conduziam o líquido a tubos coletores graduados, sendo um para cada canaleta, padronizados de acordo com a norma ISO 5682/1 (ISO, 1986). Cada ponta testada foi posicionada sobre a canaleta de número 34(central), à altura de $0,40 \mathrm{~m}$. O tempo total de pulverização para cada amostragem foi estipulado considerando o preenchimento de $90 \%$ de volume de calda da proveta que recebeu maior quantidade de líquido. Foram utilizadas três unidades de cada ponta, instaladas isoladamente no centro da mesa, de modo que o jato fosse lançado na posição vertical. Utilizaram-se os modelos TF4, TTI e AIUB11004VS nas pressões de 3, 5 e 4 bar, respectivamente, simulando volumes de aplicação em torno de $150 \mathrm{~L} \mathrm{ha}^{-1}$, com velocidade de $16 \mathrm{~km}$ $\mathrm{h}^{-1}$ comumente utilizadas em áreas de cana-de-açúcar, para a aplicação de inseticidas com autopropelido.

Para cada modelo, trabalhou-se com calda preparada a base de Metarhizium anisopliae (38g10 $\mathrm{L}^{-1}$ de água), M. anisopliae + Agral (2\%) e M. anisopliae + Agral (4\%). A calda foi preparada em tanque de aço inoxidável com capacidade volumétrica de 10L, pressurizado com ar comprimido proporcionado por um compressor modelo MSV-5,2VL 130, pressão máxima de 8,27bar (120lbf pol$^{-2}$ ) e deslocamento de ar de 155L $\mathrm{min}^{-1}$ (Metalúrgica Schulz S.A.). 
Com base nos volumes médios coletados nas repetições, em cada tratamento, foram determinados os perfis de distribuição volumétrica de cada ponta, com posterior simulação do padrão médio de distribuição volumétrica ao longo da barra de pulverização, o qual foi determinado em software (Microsoft Excel) (FREITAS et al., 2005). A análise da distribuição volumétrica das pontas de pulverização foi realizada pelo cálculo do coeficiente de variação (CV) da sobreposição dos jatos, sendo que o coeficiente de variação considerado neste trabalho para determinar o espaçamento entre bicos foi de até $10 \%$, dentro do limite aceitável na literatura (WOLF \& SMITH, 1979; FAO, 1997).

Por ocasião da análise do perfil de distribuição volumétrica, foi realizada a coleta de líquido de cada ponta em 60 segundos, para se avaliar a vazão, e foi aferido o ângulo de abertura dos jatos de calda, por meio de goniômetro analógico. Para esses dados, o delineamento foi inteiramente casualizado, em esquema fatorial $3 \times 3$, com três repetições, em que o primeiro fator representa o modelo de bico utilizado e o segundo fator o tipo de calda. As médias dos dados de vazão e ângulo de abertura dos jatos foram então comparadas pelo teste de Tukey a $1 \%$ de probabilidade.

\section{RESULTADOS E DISCUSSÃO}

Na figura 1, estão apresentadas as curvas de deposição dos bicos TF4, TTI e AIUB11004VS. A distribuição de gotas foi adequada para todos os bicos, independente da adição de adjuvante. No entanto, os bicos TF4 e TTI apresentaram maior volume de calda no centro e gradativa redução da quantidade de calda nas extremidades, conforme preconizado pelo fabricante(TEEJET TECHNOLOGIES, 2008). Esse perfil é indicado para aplicação em área total, com sobreposição de jatos (MATUO et al., 2001). Já o bico AIUB11004VS apresentou depósito de líquido uniforme na área central e decréscimo abrupto nas extremidades. Esse perfil de distribuição é indicado para aplicação em faixa, sem a sobreposição de jatos (MATUO et al., 2001). No entanto, observou-se que cada bico apresentou comportamento diferente de distribuição em relação à calda de pulverização.

O bico TF4 depositou maiores volumes de calda de pulverização quando aplicada calda com $4 \%$ do adjuvante, sendo que a calda com $2 \%$ de adjuvante apresentou os menores valores de deposição no centro do jato de pulverização (Figura 1).

O bico TTI apresentou maiores valores de deposição no centro do jato de pulverização, ou seja, ocorreu concentração da calda no centro da mesa, quando aspergido fungo sem adjuvante, seguido de calda com
2\% e 4\% de adjuvante. O mesmo comportamento foi observado para o bico AIUB11004VS (Figura 1).

Para os testes de sobreposição, houve variação da distância máxima entre bicos tolerada para cada ponta, sendo essas distâncias influenciadas pela adição de adjuvante na calda de pulverização (Figuras 1 e 2).

O bico TF4, sem a adição de adjuvante na calda, apresentou distância máxima tolerada de espaçamento entre os bicos de aproximadamente $75 \mathrm{~cm}$, o que corresponde a valor de CV próximo a 10\% (Figura 2 A). O valor de CV máximo estipulado para o bico está de acordo com dados obtidos por PERECIN et al. (1998). Os autores sugerem, para experimentos desenvolvidos em condições de laboratório, que os coeficientes de variação aceitáveis na prática devem ser até 10\%, uma vez que, em condições de campo, tais valores tendem a aumentar, quer pelas condições climáticas inerentes por ocasião da aplicação, quer pelos movimentos desordenados da barra de pulverização.

Nesse sentido, o aumento dessa distância acarreta em perda de uniformidade na pulverização, ou seja, o volume de calda aplicado no alvo torna-se heterogêneo. O CV de $0 \%$ indica que um mesmo volume foi aplicado ao longo de toda a barra de pulverização, o que implica pulverização com uniformidade absoluta. De acordo com PERECIN et al. (1998), o volume de aplicação deve ser o mais uniforme possível, sob pena de ser necessário volume adicional para compensar os pontos ou faixas que receberam menor quantidade de calda.

Este nível de uniformidade da calda aplicada no alvo pode acarretar em uma grande variação de conídios do fungo presentes na calda em contato com o inseto. Dessa maneira, alguns insetos podem entrar em contato com pouca quantidade de conídios, dosagem esta subletal, ocorrendo controle ineficiente da cigarrinha.

Com a adição de surfactante a $2 \%$, a distância máxima aceita entre bicos foi de $85 \mathrm{~cm}$. Desse modo, o adjuvante na concentração testada contribuiu com a produção de gotas mais homogêneas, acarretando em distribuição de calda mais uniforme (Figura 2 B). O ganho de $10 \mathrm{~cm}$ de distância do espaçamento de bicos em relação à calda sem adjuvante proporciona diminuição do número de bicos no pingente, visando o controle de cigarrinha. A redução do número de pontas proporciona economia no gasto de calda de pulverização e maior rendimento operacional, reduzindo custos e contribuindo para uma menor aplicação de inseticidas, agregando melhorias no manejo dessa praga e na sustentabilidade da cultura.

Porém, os testes com calda contendo 4\% do adjuvante não proporcionaram aumento da distância entre pontas. Para esse tratamento, a distância máxima tolerada entre pontas foi de aproximadamente $55 \mathrm{~cm}$ (Figura 2 C). 


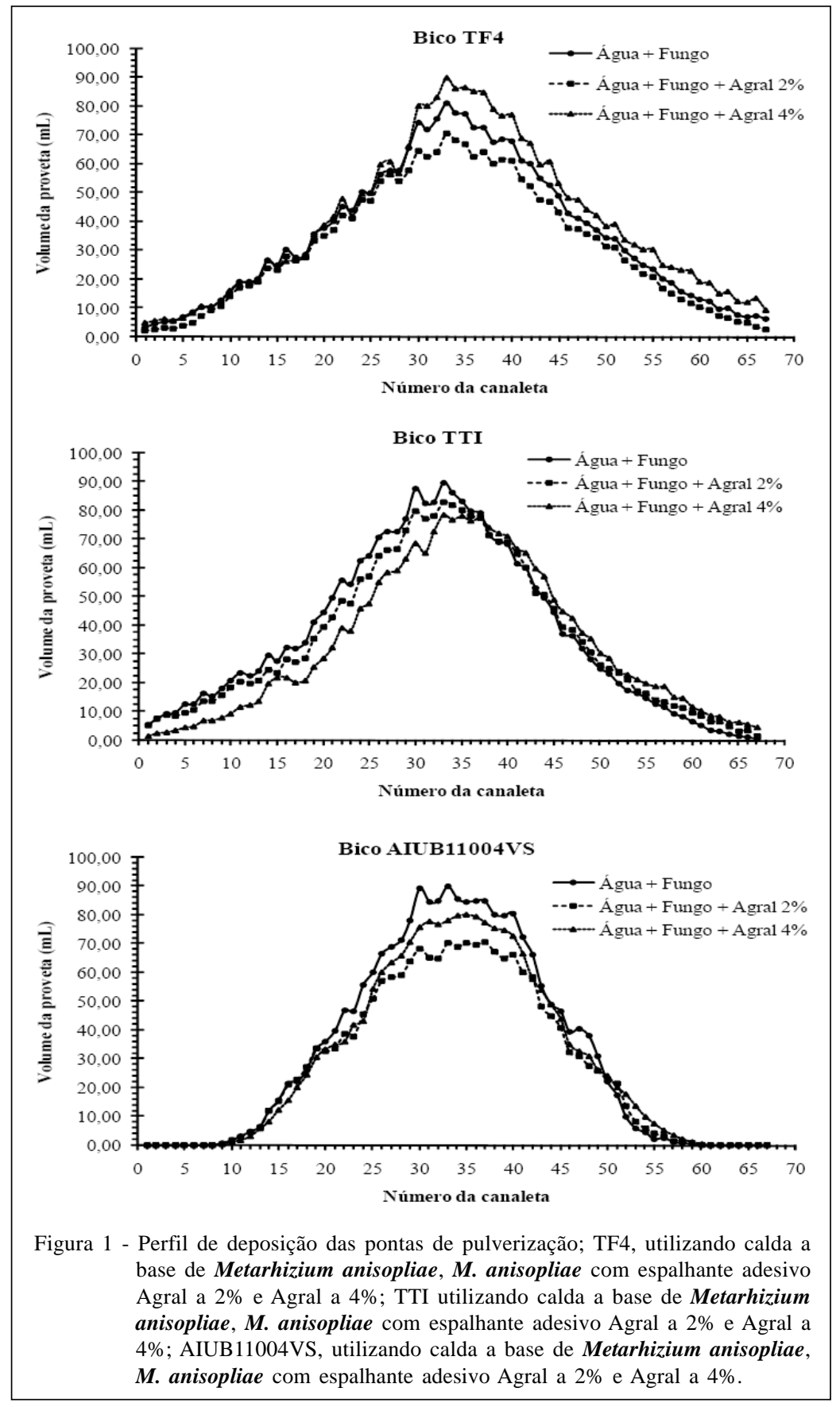

As pontas TTI apresentaram comportamento semelhante em relação às caldas testadas. Independente do aumento da concentração de surfactante na calda de pulverização, a distância máxima permitida entre bicos é de aproximadamente $55 \mathrm{~cm}$, que caracteriza baixa perda de uniformidade na aplicação (Figura 2 D, E e F).

Fato semelhante ocorrido para as pontas TTI foi evidenciado para os tratamentos com as pontas AIUB11004VS. Para essa ponta, a adição de adjuvante na calda não influenciou na distância entre bicos, que foi de aproximadamente $70 \mathrm{~cm}$ para a calda sem adjuvante e entre 65 a 67,5 para as caldas com adjuvante a 2\% e 4\%. FERREIRA et al. (2009), testando pulverização de calda herbicida com o bico AIUB025 a distâncias de 0,$8 ; 1,0 ; 1,2$ e 1,5m, observaram que somente o espaçamento de $0,85 \mathrm{~m}$ entre pontas proporcionou CV aceitável (Figura 2 G, H e I).

Na tabela 1, observa-se que o ângulo de abertura dos bicos de pulverização foi semelhante para 


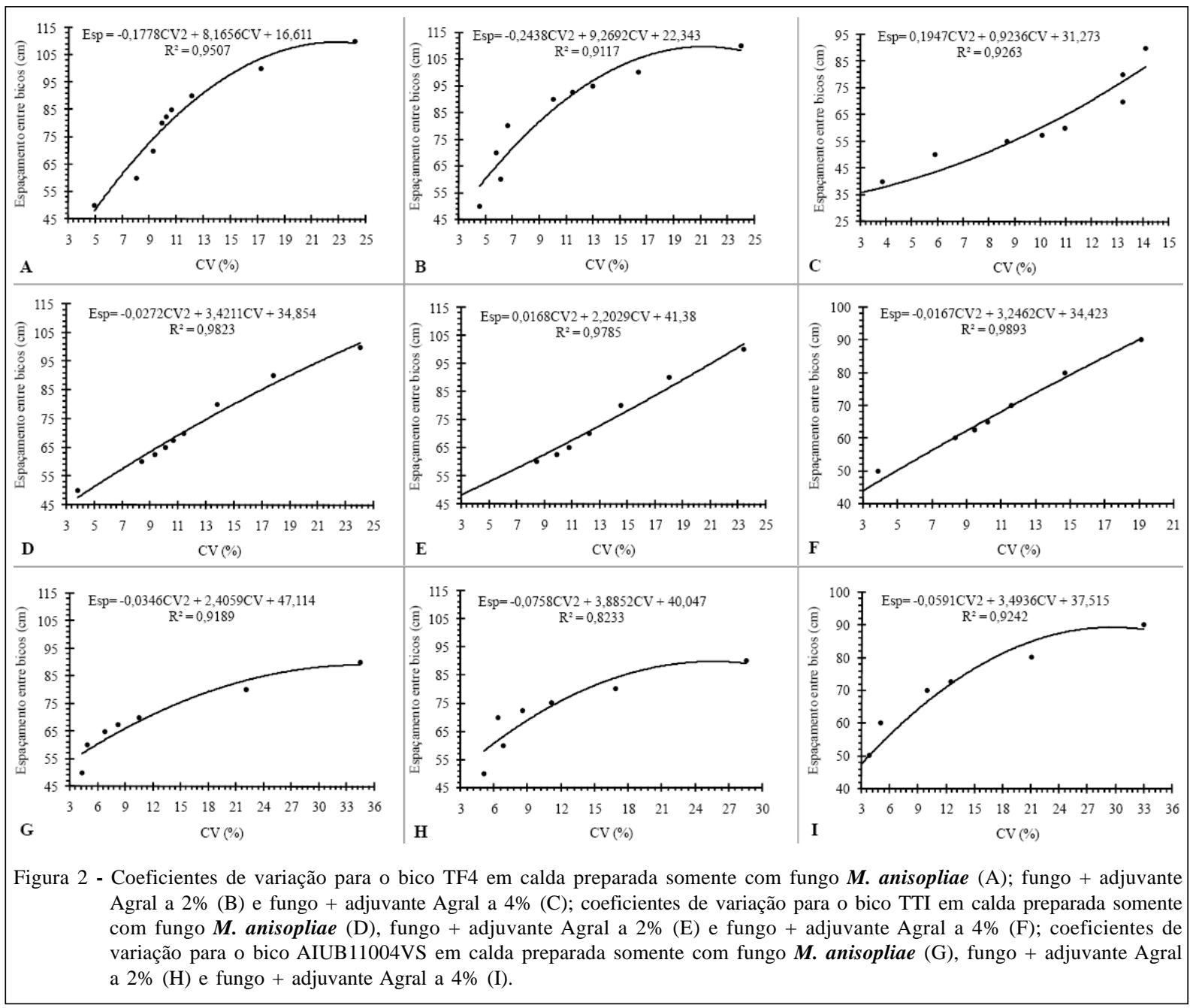

todas as caldas testadas. Quando os bicos foram comparados para uma mesma calda, ocorreu diferença significativa entre estes. Dessa maneira, o bico TF4 apresentou ângulo de abertura maior em relação ao bico AIUB11004VS, para todas as caldas testadas (água + fungo; água+fungo+adjuvante a $2 \%$ e água+fungo+adjuvante a $4 \%$ ), porém não se diferiu significativamente do bico TTI para todas as caldas. AIUB11004VS e TTI diferiram significativamente para as caldas contendo somente fungo e fungo com adjuvante a $2 \%$, com menores valores de ângulo de abertura para o primeiro bico.

A vazão foi significativamente diferente entre os bicos testados, com a adição de $2 \%$ e $4 \%$ de adjuvante na calda, sendo que TF4 apresentou os maiores valores de vazão e AIUB11004VS, os menores. Em calda sem adjuvante, não houve diferença significativa entre os bicos. Comparando-se a vazão da calda em um mesmo bico, observou-se que TF4 e TTI apresentaram maiores valores quando adicionado 4\% de adjuvante em relação à calda sem adjuvante. O modelo AIUB11004VS não apresentou variações na vazão com adição do adjuvante, não havendo diferença significativa entre as caldas testadas para esse bico (Tabela 1).

O aumento da vazão e ângulo de abertura está intimamente relacionado com a pressão de trabalho dos bicos. Dessa maneira, quanto maior a pressão de trabalho, maior será a vazão e ângulo de abertura (VIANA et al., 2010; 2008; FERNANDES et al., 2007; FERREIRA et al., 2009). Porém, o presente trabalho não teve como objetivo avaliar a influência da pressão de trabalho na vazão e ângulo de abertura, sendo que a pressão de cada bico foi adotada considerando o caminhamento de $16 \mathrm{~km} \mathrm{~h}^{-1}$ e volume de $150 \mathrm{~L} \mathrm{ha}^{-1}$, o que é comumente utilizado em pulverização de fungo entomopatogênico em pulverizações com autopropelido.

Dessa maneira, embora haja diferença nos valores de pressão para cada bico testado, o 
Tabela 1 - Ângulo de jato de pulverização e vazão para três modelos de bicos com três caldas de pulverização a base de Metarhizium anisopliae.

\begin{tabular}{|c|c|c|c|c|c|}
\hline Bicos & Água+ M. anisopliae & Água + M. anisopliae+ Agral 2\% & Água + M. anisopliae + Agral 4\% & CV (\%) & DMS \\
\hline \multicolumn{6}{|c|}{ 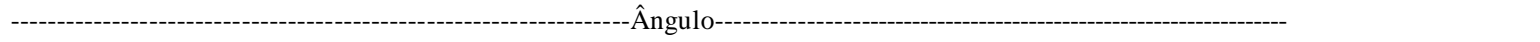 } \\
\hline TF4 & 140,33Аа & 140,00Aa & 151,33Аа & 5,18 & 18,68 \\
\hline TTI & 143,67Aa & 139,33Аа & 129,67Aab & 7,86 & 27,10 \\
\hline AIUB11004VS & $114,00 \mathrm{Ab}$ & $110,33 \mathrm{Ab}$ & $109,67 \mathrm{Ab}$ & 2,18 & 6,08 \\
\hline CV (\%) & 3,98 & 4,48 & 8,29 & & \\
\hline DMS & 13,23 & 14,59 & 27,06 & & \\
\hline & & --------Vazão (mL min' $\left.{ }^{-1}\right)$ - & & CV (\%) & DMS \\
\hline TF4 & $2.073,33 \mathrm{Ba}$ & 2.106,66ABa & $2.650,00 \mathrm{Aa}$ & 9,79 & 128,65 \\
\hline TTI & 1.713,33Ba & $1.813,33 \mathrm{ABb}$ & $2.030,00 \mathrm{Ab}$ & 4,85 & 51,82 \\
\hline AIUB11004VS & $1.540,00 \mathrm{Aa}$ & $1.366,67 \mathrm{Ac}$ & 1.633,33Ac & 8,66 & 75,62 \\
\hline CV (\%) & 13,43 & 3,59 & 5,62 & & \\
\hline DMS & 137,71 & 36,51 & 68,26 & & \\
\hline
\end{tabular}

Médias seguidas de mesma letra minúscula na coluna e maiúscula na linha não diferem entre si pelo Teste de Tukey ao nível de $1 \%$ de probabilidade.

comportamento foi diferente em relação à distância entre bicos tolerada e à adição de adjuvantes. Pensando em reduções no volume de calda aplicado, aumento de rendimento operacional e em melhorias no que diz respeito à sustentabilidade da cultura da cana, o bico AIUB11004VS proporciona ao usuário o manejo com distância entre bicos de $70 \mathrm{~cm}$, sendo maior que o bico TTI e $15 \mathrm{~cm}$ menor do que o bico TF4, sem comprometimento de sua uniformidade de distribuição de calda. Apesar de apresentar desvantagem em relação ao bico TF4 quanto ao espaçamento, o modelo AIUB11004VS proporciona economia no consumo de calda de quase $0,8 \mathrm{~L}$, usando $2 \%$ de adjuvante e, nessas condições, ainda pode ser utilizado com maior espaçamento na barra de pulverização. Dessa maneira, o modelo AIUB11004VS apresenta maior dinamismo em sua utilização no manejo da cigarrinha da cana, o que pode acarretar em melhorias na tecnologia de aplicação do fungo M. anisopliae, visando ao controle de $\boldsymbol{M}$. fimbriolata.

\section{CONCLUSÃO}

O modelo AIUB11004VS se apresenta como uma boa opção, visando o controle de Mahanarva fimbriolata, por resultar em baixo consumo de calda e espaçamento entre bicos de $70 \mathrm{~cm}$.

O modelo TF4, apesar de apresentar maior consumo de calda, pode ser considerado como alternativa, pelo fato de possibilitar o uso com espaçamentos maiores entre bicos $(85 \mathrm{~cm})$ ou a aplicação em menores alturas, mantendo boa qualidade na distribuição.

\section{REFERÊNCIAS}

ALMEIDA, J.E.M. et al. Avaliação do controle biológico de Mahanarva fimbriolata (Hom., Cercopidae) com o fungo Metarhizium anisopliae em variedades de cana-de-açúcar e diferentes épocas de corte. Arquivos Instituto Biológico, v.70, n.1, p.101-103, 2003. Disponível em: <http:// www.biologico.sp.gov.br/docs/arq/V70_1/almeida2.pdf $>$. Acesso em: 29 set. 2010.

ALVES, S.B.; ALMEIDA, J.E.M. Controle biológico das pragas das pastagens. In: SIMPÓSIO SOBRE ECOSSISTEMA DE PASTAGENS, 3., 1997, Jaboticabal, SP. Anais... Jaboticabal: FCAV/UNESP, 1997. p.318-341.

DINARDO-MIRANDA, L.L. et al. Eficiência de Metarhizium anisopliae (Metsch.) no controle de Mahanarva fimbriolata (Stål) (Hemiptera: Cercopidae) em cana-de-açúcar. Neotropical Entomology, v.33, n.6, p.743-749, 2004. Disponível em: <http://www.scielo.br/pdf/ne/v33n6/23346.pdf>. Acesso em: 29 set. 2010. doi: 10.1590/S1519-566X2004000600012.

FAO. Food Agriculture and Organization. Equipo de aplicación de pesticida para uso en agricultura: equipo impulsado mecánicamente. ROMA, 1997. V.2, 150p.

FERNANDES, A.P. et al. Caracterização do perfil de deposição e do diâmetro de gotas e otimização do espaçamento entre bicos na barra de pulverização. Engenharia Agrícola, v.27, n.3, p.728-733, 2007. Disponível em: <http://www.scielo.br/ pdf/eagri/v27n3/a16v27n3.pdf>. Acesso em: 24 ago. 2010. doi: 10.1590/S0100-69162007000400016.

FERREIRA, M. C. et al. Distribuição da calda herbicida por pontas de pulverização agrícola utilizadas em áreas de reflorestamento com eucalipto. Engenharia Agrícola, v.29, n.2, p.267-276, 2009. Disponível em: <http://www.scielo.br/ pdf/eagri/v29n2/10.pdf >. Acesso em: 24 ago. 2010. doi:10.1590/S0100-69162009000200009.

FREITAS, F.C.L. et al. Distribuição volumétrica de pontas de pulverização Turbo Teejet 11002 em diferentes condições 
operacionais. Planta Daninha, v.23, n.1, p.161-167, 2005. Disponível em: <http://www.scielo.br/pdf/pd/v23n1/23940.pdf>. Acesso em: 03 set. 2010. doi: 10.1590/S0100-83582005000100019.

INTERNATIONAL ORGANIZATION FOR STANDARDIZATION - ISO. Equipment for crop protection - Spraying equipment Part 2: test methods for agricultural sprayers. Geneva, 1986. 5p. (ISO 5682/2).

MACEDO, N. et al. Insetos nas raízes e colo da planta, perfilhamento e produtividade em canaviais colhidos com e sem queima. STAB Açúcar, Álcool e Subprodutos, v.15, n.3, p.18-21, 1997.

MATTHEWS, G.A. Pesticide application methods. London: Blackwell Science, 2000. 448p.

MATUO. T. Técnicas de aplicação de defensivos agrícolas. Jaboticabal: Funep, 1990. 139p.

MATUO, T. et al. Tecnologia de aplicação e equipamentos In: ABEAS - Curso de proteção de plantas. Módulo 2. Brasília, DF: ABEAS; Viçosa, MG: UFV, 2001. 85p.
PERECIN, D. et al. Padrões de distribuição obtidos com bicos TFVS4, TJ60-11006 e TQ15006 em mesa de prova. Pesquisa Agropecuária Brasileira, v.33, n.2, p.175-182, 1998. Disponível em: <http://webnotes.sct.embrapa.br/pab/pab.nsf/ e c d 4 c a $3 \mathrm{fff} 88$ e f c f a 032564 c d 004 e a $083 /$ 904b1e72d64ee810032565ad007788b4?OpenDocument>. Acesso em: 25 set. 2010

TEEJET TECHNOLOGIES. Catálogo 50A-P. Wheaton: Spraying Systems, 2008. 192p.

VIANA, R.G. et al. Distribuição volumétrica e espectro de gotas de ponta s de pulverização de baixa deriva. Planta Daninha, v.28, n.2, p.439-446, 2010. Disponível em: <http:/ /www.scielo.br/pdf/pd/v28n2/a24v28n2.pdf>. Acesso em: 24 ago. 2010. doi: 10.1590/S0100-83582010000200024.

WOLF, D.D.; SMITH, E.S. Uniformity of seed and fertilizer distribution with a hand-operatedspinning spreader. Transactions of the ASAE, v.22, n.4, p.761-762, 1979. 